\title{
Combined electronic structure and evolutionary search approach to materials design
}

Johannesson, Gisli Holmar; Bligaard, Thomas; Ruban, Andrei; Skriver, Hans Lomholt; Jacobsen, Karsten Wedel; Nørskov, Jens Kehlet

Published in:

Physical Review Letters

Link to article, DOI:

10.1103/PhysRevLett.88.255506

Publication date:

2002

Document Version

Publisher's PDF, also known as Version of record

Link back to DTU Orbit

Citation (APA):

Johannesson, G. H., Bligaard, T., Ruban, A., Skriver, H. L., Jacobsen, K. W., \& Nørskov, J. K. (2002). Combined electronic structure and evolutionary search approach to materials design. Physical Review Letters, 88(25), 255506. https://doi.org/10.1103/PhysRevLett.88.255506

\section{General rights}

Copyright and moral rights for the publications made accessible in the public portal are retained by the authors and/or other copyright owners and it is a condition of accessing publications that users recognise and abide by the legal requirements associated with these rights.

- Users may download and print one copy of any publication from the public portal for the purpose of private study or research.

- You may not further distribute the material or use it for any profit-making activity or commercial gain

- You may freely distribute the URL identifying the publication in the public portal

If you believe that this document breaches copyright please contact us providing details, and we will remove access to the work immediately and investigate your claim 


\title{
Combined Electronic Structure and Evolutionary Search Approach to Materials Design
}

\author{
G. H. Jóhannesson, T. Bligaard, A. V. Ruban, H. L. Skriver, K. W. Jacobsen, and J. K. Nørskov \\ Center for Atomic-Scale Materials Physics, Department of Physics, Technical University of Denmark, \\ DK-2800, Lyngby, Denmark
}

(Received 20 February 2002; published 10 June 2002)

\begin{abstract}
We show that density functional theory calculations have reached an accuracy and speed making it possible to use them in conjunction with an evolutionary algorithm to search for materials with specific properties. The approach is illustrated by finding the most stable four component alloys out of the 192016 possible fcc and bcc alloys that can be constructed out of 32 different metals. A number of well known and new "super alloys" are identified in this way.
\end{abstract}

DOI: 10.1103/PhysRevLett.88.255506

PACS numbers: 81.05.Bx, 61.66.Dk, 71.15.Mb

With the advent of efficient methods based on density functional theory (DFT) it is possible today to describe many properties of materials from first principles [1,2]. In some cases one has even been able to predict new material compositions with interesting properties [3-5]. In the present Letter we show that the theoretical methods have reached a level of accuracy and speed where they can be used to search more systematically for new materials. To do so, we address the following question: Which are the most stable four-component alloys? In our search we consider all four combinations of 32 transition, noble, and simple metals in fcc- and bcc-based structures, and out of a total of 192016 possibilities we identify the 20 most stable. This is made possible by combining the DFT calculations with an evolutionary algorithm in the search for the optimum configurations. We show that the optimization with respect to stability can be combined with requirements relating to structure or price.

We focus here on the heat of formation of fourcomponent alloys. If, for instance, the aim is to design high-performance alloys [6], knowing the stability is a good starting point, since it determines whether a given material can exist or not. In addition, the stability of a single-phase intermetallic compound determines to a large extent the resistance of the alloy to different kinds of applied external conditions - stress, high temperature, or irradiation. Finally, the heat of formation is a property that can be calculated directly from electronic structure theory - it is a microscopic quantity reflecting the quantum properties of the electron system.

In the following we first show that DFT can accurately describe variations in stability from one alloy to the next. This is done for binary alloys where there is a large experimental database to compare to. We also use the binary alloys to illustrate the ability of our evolutionary algorithm to search effectively for the most stable alloy. We then turn to the four-component alloys and show how we can identify a population of the most stable alloys, and show that one can apply different constraints by, e.g., requiring a specific crystal structure or by excluding certain high cost metals.
Our DFT calculations have been performed by the linear muffin-tin orbital method (LMTO) [7] except for those cases involving $\mathrm{Zn}, \mathrm{Cd}, \mathrm{Hg}$, Lu, and Si where the KorringaKohn-Rostocker (KKR) method [8] was used to ensure an accurate description of the low-lying valence or semicore states. The atomic sphere approximation used throughout has been corrected by the contribution from the multipole moments of the charge density to the electrostatic potential and the total energy [8]. The $k$-point sampling used about $2000 k$ points in the full Brillouin zone for the four-atom supercells of both fcc-type and bcc-type alloys. Exchange and correlation effects were treated within the framework of the generalized gradient approximation (GGA) [9]. For each alloy and structure we performed self-consistent electronic-structure calculations for at least four different lattice spacings to find the energy minimum. We did not take structural relaxations into account.

When we compare our calculated enthalpies of formation with experimental data [10] for binary alloys, Fig. 1, the agreement is very good. This is particularly so in view of the fact that different experimental data for the same intermetallic compound frequently scatter by $20 \%$,

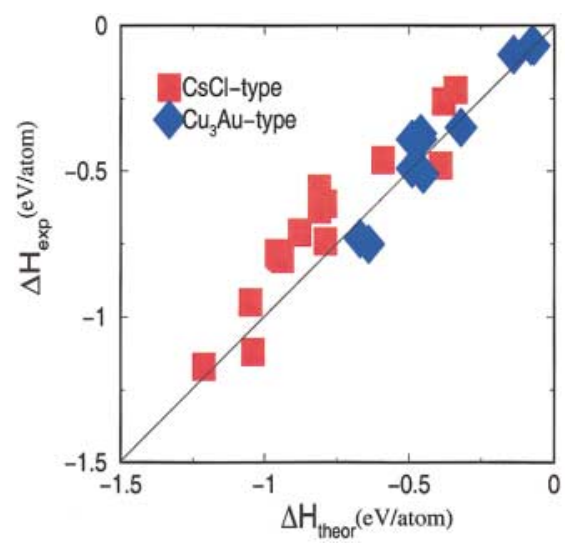

FIG. 1 (color). Comparison of experimental [10] and calculated heats of formation for binary alloys. We have included all cases where the experimentally observed structure corresponds to the calculated one, which is the fcc-based $\mathrm{Cu}_{3} \mathrm{Au}-$ and $\mathrm{CuAu}$-type structures or the bcc-based $\mathrm{CsCl}$-type structure. 
reflecting the considerable experimental problems associated with measuring enthalpies of formation.

The idea of the evolutionary algorithm is to search for alloys with improved properties, from a population of alloys, which undergoes a simple Darwinistic evolution [11,12]. To represent a "living population," a set of alloys is chosen. Each alloy in the population is represented by a genetic code - a list of its four constituent elements from the periodic table, which occupy the corresponding four sites in either bcc or fcc supercells. New populations are created by letting the population undergo natural evolution in the sense of breeding between the alloys, mutation, and selection of the fittest alloys to survive to the next population. These three steps are repeated until a convergence criterion is fulfilled. Initially a population of alloys is created by picking elements, at random, from the elements included in this study. Starting from totally random initial populations several times, and always ending up with the same final population gives a good check for the stability of the algorithm. Breeding is performed by randomly picking two "parent alloys" from the population, and interchanging one or two randomly chosen elements from each parent, giving two "children alloys." The mutation is done by changing one element to another element in the periodic table. Selection of the fittest consists of picking out the most stable alloys found among the earlier population, the children and the mutants. Given the computational effort needed to arrive at the converged generation, we did not optimize our choice of parameters for the algorithm (i.e., number of children, etc., per generation).

Consider first the 992 different $\mathrm{A}_{3} \mathrm{~B}$ binary alloys in the fcc-like $\mathrm{L}_{2}$ structure of the 32 elements we are considering here; see Fig. 2. Even the problem of finding the most stable binaries in this one structure is not a simple one. The stability landscape is rugged with many local minima. It has an inherent structure, which is evident by the trend in stability among neighboring alloys. Searching this alloy space with an elaborate algorithm, rather than a random search, is justified by this apparent structure, which is a reflection of the inherent structure of the periodic table of elements. Running an evolutionary algorithm on this set gave the best ten alloys after about 250 individual alloy calculations. This is considerably better than, e.g., a simple zero temperature Monte Carlo method, and shows the power of the evolutionary algorithm even for such a small problem where it cannot show its full potential [13].

We apply the evolutionary algorithm described above to determine which are the most stable alloys with up to four components. We exclude ternary and quaternary alloys which phase separate into binary components. Figure 3 illustrates how the formation energy evolves from generation to generation until there is no further improvement. In Table I(a) we present the 20 most stable alloys and their formation energies.

All the most stable alloys in Table I(a) prefer the bcc structure to fcc. They typically involve an equal number of early and late transition metals. The average number

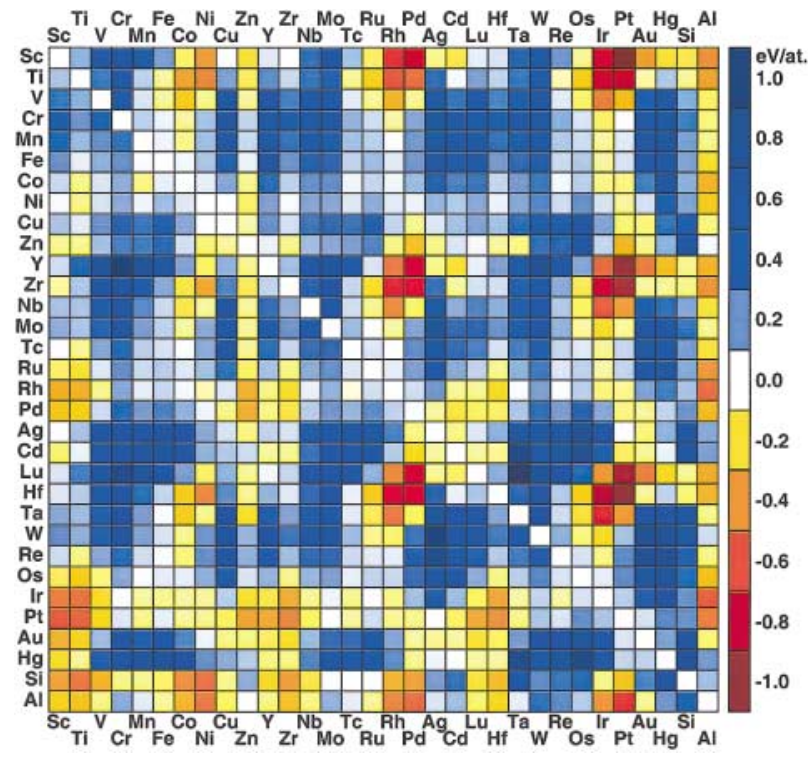

FIG. 2 (color). Enthalpies of formation for the fcc-like $\mathrm{L}_{2}$ structure of binary alloys. Horizontally are the elements of $75 \%$ abundance in the binary alloy, vertically are the elements of $25 \%$ abundance.

of $d$ electrons per bond is therefore about five, and the $d$ bands are thus half filled, making only the bonding states occupied. This is analogous to the elemental metals where the strongest cohesion is also found for $\mathrm{W}$ or Mo, which have half filled $d$ shells and prefer the bcc structure [14,15].

The bcc metals are usually less interesting than fcc or hcp metals as structural materials because they tend to be less ductile [16]. We therefore consider another procedure where we add the requirement that an alloy must be more stable in the fcc than in the bcc structure to survive in the optimization process. The resulting set of alloys is shown in Table I(b). They still typically involve early and late transition metals, and in addition they all involve noble metals like Pd or Pt. This means that even though these alloys may be of interest for special purposes, they are far too expensive for most applications as structural materials. We therefore made yet another set of runs, where we excluded the most expensive, noble metals Ag, $\mathrm{Au}, \mathrm{Pd}, \mathrm{Pt}, \mathrm{Rh}$, and Ir.

Now a completely different resulting population emerges, Table I(c). The new list is dominated by transition metal silicides. They are known to have a high hardness, but are also brittle. $\mathrm{Ni}_{3} \mathrm{Si}$ has the $\mathrm{L1}_{2}$-type structure, and is ductile in vacuum, but environmentally brittle (which is a common problem of many silicides). Nevertheless, alloys based on $\mathrm{Ni}_{3} \mathrm{Si}$, namely $\mathrm{Ni}_{3}(\mathrm{Si}, \mathrm{Ti})$, are considered as candidates for high temperature structural materials and chemically resistant parts [6], and we note that three different combinations $\left(\mathrm{Ni}_{3} \mathrm{Si}, \mathrm{NiSiTi}_{2}\right.$, and $\mathrm{Ni}_{3} \mathrm{Ti}$ ) of these three elements are on the list.

In order to provide a more diverse list of stable alloys we performed yet another evolution where we excluded $\mathrm{Si}$ as well as the expensive metals, Table $\mathrm{I}(\mathrm{d}) . \mathrm{Ni}_{3} \mathrm{Al}$, the best existing superalloy [6], is now at the top of the list. The 


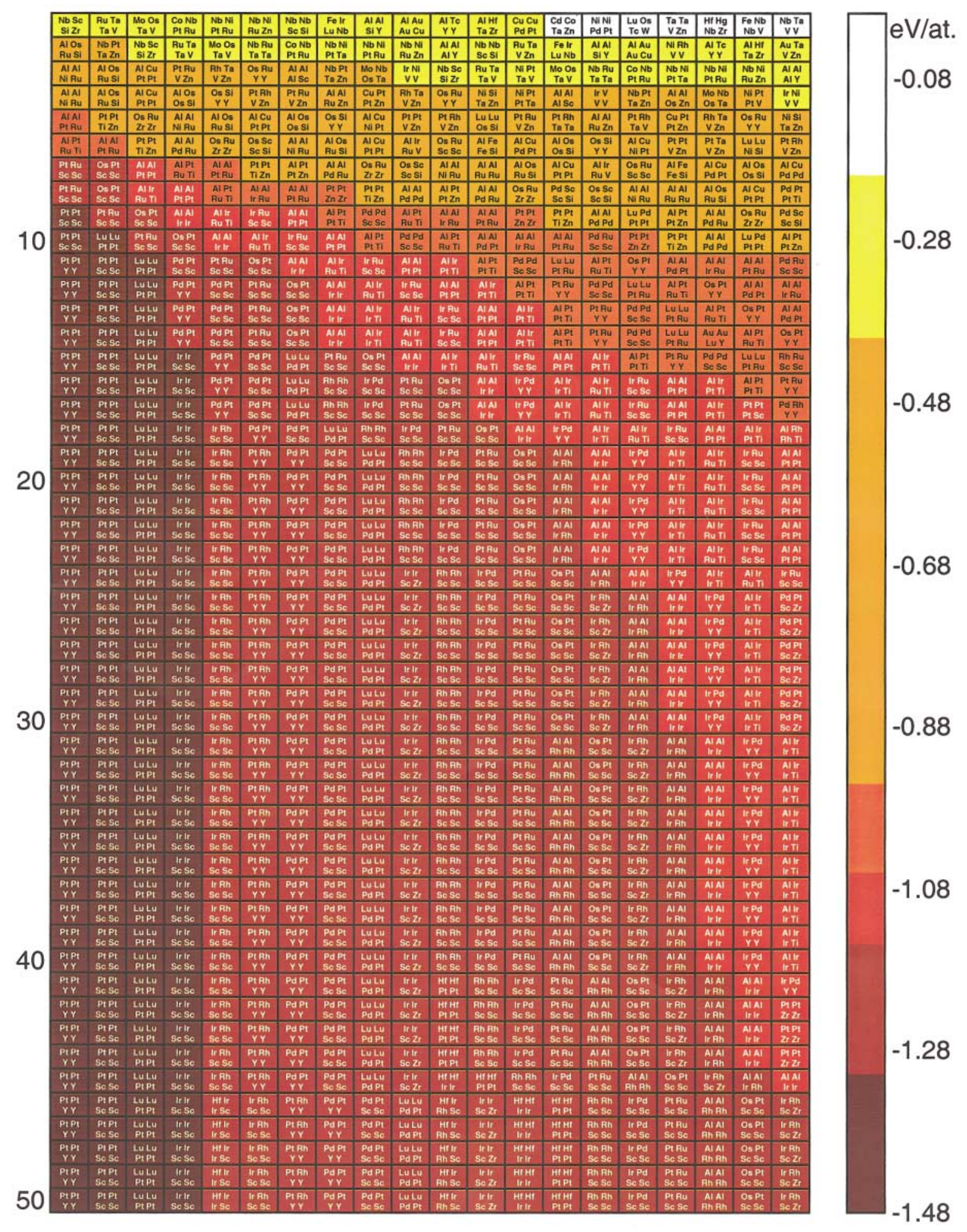

FIG. 3 (color). Evolution of the formation energy for a population of alloys. Each alloy is represented by a single box. The color in the box gives the range in which its formation energy lies. Each generation is represented by a horizontal row of boxes (twenty per generation). The initial generation is at the top and the evolution proceeds downwards. The first 50 generations are shown. No improvement was observed in the following 50 generations. The last generation of alloys is given in Table I.

next one, $\mathrm{Ni}_{3} \mathrm{Ti}$, has actually a hexagonal $\mathrm{DO}_{24}$ structure and thus cannot be used itself as a basis for structural alloys. However, $\mathrm{Ti}$ is the main alloying component in both $\mathrm{Ni}_{3} \mathrm{Si}\left[\mathrm{Ni}_{3}(\mathrm{Si}, \mathrm{Ti})\right]$ and $\mathrm{Ni}_{3} \mathrm{Al}$. TiAl (has $\mathrm{L1}_{0}$ structure) is a well known intermetallic compound which together with $\mathrm{TiAl}_{3}$ (13th on the list) have been extensively developed for commercial applications as high-temperature superalloys for more than two decades. Among the rest of the 
TABLE I. The twenty most stable alloys, with up to four components. (a) All alloys, (b) fcc most stable, (c) Noble metals excluded, and (d) Si excluded in addition to noble metals.

\begin{tabular}{|c|c|c|c|c|c|c|c|}
\hline (a) & $\Delta H_{f}(\mathrm{eV} /$ atom $)$ & (b) & $\Delta H_{f}(\mathrm{eV} /$ atom $)$ & (c) & $\Delta H_{f}(\mathrm{eV} /$ atom $)$ & (d) & $\Delta H_{f}(\mathrm{eV} /$ atom $)$ \\
\hline $\mathrm{Pt}_{2} \mathrm{Y}_{2}$ & -1.48 & $\mathrm{Pt}_{3} \mathrm{Sc}$ & -1.06 & $\mathrm{Si}_{2} \mathrm{Ti}_{2}$ & -0.57 & $\mathrm{AlNi}_{3}$ & -0.49 \\
\hline $\mathrm{Pt}_{2} \mathrm{Sc}_{2}$ & -1.47 & $\mathrm{HfPt}_{3}$ & -1.03 & $\mathrm{NiSiTi}_{2}$ & -0.55 & $\mathrm{Ni}_{3} \mathrm{Ti}$ & -0.46 \\
\hline $\mathrm{Lu}_{2} \mathrm{Pt}_{2}$ & -1.41 & $\mathrm{Pt}_{3} \mathrm{Y}$ & -1.02 & $\mathrm{Si}_{2} \mathrm{TaTi}$ & -0.53 & $\mathrm{HfNi}_{3}$ & -0.44 \\
\hline $\mathrm{Ir}_{2} \mathrm{Sc}_{2}$ & -1.35 & $\mathrm{PdPt}_{2} \mathrm{Sc}$ & -0.99 & $\mathrm{Ni}_{3} \mathrm{Si}$ & -0.53 & $\mathrm{Al}_{2} \mathrm{Ti}_{2}$ & -0.43 \\
\hline $\mathrm{HfIr}_{2} \mathrm{Sc}$ & -1.30 & $\mathrm{Pt}_{3} \mathrm{Zr}$ & -0.98 & $\mathrm{AlSiTi}_{2}$ & -0.53 & $\mathrm{Al}_{3} \mathrm{Sc}$ & -0.43 \\
\hline $\operatorname{IrRhSc}_{2}$ & -1.29 & $\mathrm{HfPt}_{2} \mathrm{Rh}$ & -0.98 & $\mathrm{Ni}_{2} \mathrm{SiTa}$ & -0.53 & $\mathrm{Al}_{2} \mathrm{Zr}_{2}$ & -0.42 \\
\hline $\mathrm{PtRhY}_{2}$ & -1.27 & $\mathrm{PdPt}_{2} \mathrm{Y}$ & -0.97 & CoNiSiTa & -0.52 & $\mathrm{Al}_{2} \mathrm{ZnZr}$ & -0.42 \\
\hline $\mathrm{PdPtY}_{2}$ & -1.27 & $\mathrm{HfPdPt}_{2}$ & -0.96 & NiSiTaTi & -0.51 & $\mathrm{Al}_{2} \mathrm{Sc}_{2}$ & -0.41 \\
\hline $\mathrm{PdPtSc}_{2}$ & -1.26 & $\mathrm{LuPt}_{3}$ & -0.95 & AlSiTaTi & -0.50 & $\mathrm{Ni}_{3} \mathrm{Sc}$ & -0.41 \\
\hline $\mathrm{Lu}_{2} \mathrm{PdPt}$ & -1.24 & $\mathrm{Pt}_{2} \mathrm{RhSc}$ & -0.94 & $\mathrm{Sc}_{2} \mathrm{Si}_{2}$ & -0.50 & $\mathrm{Al}_{3} \mathrm{Zr}$ & -0.40 \\
\hline HfIrRhSc & -1.23 & $\mathrm{NiPt}_{2} \mathrm{Sc}$ & -0.93 & CoSiTaTi & -0.50 & $\mathrm{Al}_{2} \mathrm{TiZn}$ & -0.39 \\
\hline $\mathrm{Ir}_{2} \mathrm{ScZr}$ & -1.23 & $\mathrm{Pt}_{2} \mathrm{RhZr}$ & -0.92 & $\mathrm{AlNi}_{3}$ & -0.49 & $\mathrm{Al}_{2} \mathrm{ScZn}$ & -0.38 \\
\hline $\mathrm{Hf}_{2} \mathrm{Ir}_{2}$ & -1.23 & $\mathrm{HfNiPt}_{2}$ & -0.92 & $\mathrm{SiTi}_{3}$ & -0.49 & $\mathrm{Al}_{3} \mathrm{Ti}$ & -0.38 \\
\hline $\mathrm{Hf}_{2} \mathrm{Pt}_{2}$ & -1.21 & $\mathrm{LuPdPt}_{2}$ & -0.92 & $\mathrm{Si}_{2} \mathrm{Zr}_{2}$ & -0.47 & $\mathrm{Co}_{3} \mathrm{Ti}$ & -0.38 \\
\hline $\mathrm{Rh}_{2} \mathrm{Sc}_{2}$ & -1.21 & $\mathrm{PdPt}_{2} \mathrm{Zr}$ & -0.92 & $\mathrm{AlSc}_{2} \mathrm{Si}$ & -0.46 & $\mathrm{Ni}_{3} \mathrm{Zr}$ & -0.36 \\
\hline $\mathrm{IrPdSc}_{2}$ & -1.20 & $\mathrm{Pd}_{2} \mathrm{PtSc}$ & -0.91 & $\mathrm{Ni}_{3} \mathrm{Ti}$ & -0.46 & $\mathrm{Al}_{2} \mathrm{NbTi}$ & -0.36 \\
\hline $\mathrm{PtRuSc}_{2}$ & -1.19 & HfIrPtRh & -0.90 & NiSiTaZn & -0.46 & $\mathrm{Al}_{2} \mathrm{CuTi}$ & -0.35 \\
\hline $\mathrm{Al}_{2} \mathrm{Rh}_{2}$ & -1.18 & $\mathrm{Pd}_{2} \mathrm{PtY}$ & -0.90 & $\mathrm{AlSiZr}_{2}$ & -0.46 & $\mathrm{Al}_{2} \mathrm{HfZn}$ & -0.34 \\
\hline $\mathrm{OsPtSc}_{2}$ & -1.18 & $\mathrm{HfPtRh}_{2}$ & -0.88 & $\mathrm{SiTi}_{2} \mathrm{Zn}$ & -0.45 & $\mathrm{Al}_{2} \mathrm{CuZr}$ & -0.34 \\
\hline IrRhScZr & -1.17 & $\mathrm{HfIr}_{3}$ & -0.88 & $\mathrm{HfNi}_{3}$ & -0.44 & $\mathrm{Al}_{3} \mathrm{Lu}$ & -0.34 \\
\hline
\end{tabular}

compounds presented in the list $\mathrm{Al}_{3} \mathrm{Sc}$ is a very interesting one since it also has the fcc-like $\mathrm{L}_{2}$ structure [6]. However, until now it has been used only as a hardening precipitate in Al-Sc alloys. Only recently has it attracted attention as a promising candidate for superalloys [17]. The list contains several alloys that are not well studied or presently considered as candidates for superalloys. It includes simple binaries as well as several ternary alloys. Most of the ternary alloys, $\mathrm{Al}_{2} \mathrm{ZnZr}, \mathrm{Al}_{2} \mathrm{ZnTi}, \mathrm{Al}_{2} \mathrm{ZnSc}, \mathrm{Al}_{2} \mathrm{ZnHf}, \mathrm{Al}_{2} \mathrm{CuTi}$, and $\mathrm{Al}_{2} \mathrm{CuZr}$ actually crystallize in the $\mathrm{L1}_{2}$ structure [18-20] and should be interesting candidates. Others have more complicated structures that are not a priory interesting for structural materials, but knowing that they are intrinsically very stable might make it worthwhile to investigate if the addition of (small) amounts of other metals could be used to change the structure. Our extended search therefore gives results that confirm present knowledge about superalloys and point to new possibilities.

The development of new functional and structural materials is still based largely on trial-and-error methods. Recently these methods have been made considerably more efficient through the introduction of combinatorial or high throughput screening approaches [21-23]. It has already been realized that it is impossible to screen all material combinations experimentally, and evolutionary methods have been introduced in experimental design [24]. A "computational" laboratory is extremely well suited for studies utilizing evolutionary methods or other combinatorial techniques, and here we have shown that the present status of DFT calculations allows for such studies on simple problems. Optimization of real materials involves a large number of considerations.
High-temperature superalloys, for instance, must not only be thermally stable at high temperatures and be able to withstand high stress. They must also be ductile, corrosion resistant, and satisfy many other technical and processing requirements. For this reason a purely theoretical design of new materials is well into the future. However, approaches such as the one presented here can make the first step in such a process. By identifying a set of possible candidates satisfying a set of simple criteria we can make a good initial guess and this in itself can speed up development processes tremendously. The purely computational approach may therefore be able to narrow down the number of experiments needed for the development of new materials.

[1] D. G. Pettifor and A. H. Cottrell, Electron Theory in Alloy Design (Alden Press, Oxford, United Kingdom, 1992).

[2] J. Bernholc, Phys. Today 52, No. (9), 30 (1999).

[3] G. Ceder et al., Nature (London) 392, 694 (1998).

[4] F. Besenbacher et al., Science 279, 1913 (1998).

[5] A. Franceschetti and A. Zunger, Nature (London) 402, 60 (1999).

[6] J.H. Westbrook and R.L. Fleischer, Intermetallic Compounds: Principles and Practise (Wiley, Chichester, 1994), Vols. 1 and 2.

[7] O. K. Andersen, O. Jepsen, and D. Glotzel, in Highlights of Condensed Matter Theory, edited by F. Bassani, F. Fumi, and M. Tosi (North-Holland, New York, 1985), p. 59.

[8] A. V. Ruban and H. L. Skriver, Comput. Mater. Sci. 15, 119 (1999).

[9] Y. Wang and J. P. Perdew, Phys. Rev. B 44, 13298 (1991). 
[10] F. R. de Boer, R. Boom, W. C. M. Mattens, A. R. Miedema, and A. K. Niessen, Cohesion in Metals: Transition Metal Alloys (North-Holland, Amsterdam, 1988).

[11] J. H. Holland, Adaptation in Natural and Artificial Systems (University of Michigan Press, Ann Arbor, 1975).

[12] D. M. Deaven and K. M. Ho, Phys. Rev. Lett. 75, 288 (1995).

[13] Further information on the database of binary alloys is available online at http://www.fysik.dtu.dk/BinaryAlloys/

[14] D. G. Pettifor, Bonding and Structure of Molecules and Solids (Clarendon Press, Oxford, United Kingdom, 1995).

[15] H. L. Skriver, Phys. Rev. B 31, 1909 (1985).

[16] J. P. Hirth and J. Lothe, Theory of Dislocations (McGrawHill, New York, 1968).
[17] Y. Harada and D. C. Dunand, Acta Mater. 48, 3477 (2000).

[18] A. Raman and K. Schubert, Z. Metallkd. 56, 40 (1965).

[19] P. Virdis and U. Zwicker, Z. Metallkd. 62, 46 (1971).

[20] K. Schubert, A. Raman, and W. Rossteutscher, Naturwissenschaften 51, 506 (1964).

[21] B. Jandeleit, D. J. Schaefer, T. S. Powers, H. W. Turner, and W. H. Weinberg, Angew. Chem., Int. Ed. Engl. 38, 2494 (1999).

[22] C. Hoffmann, A. Wolf, and F. Schüth, Angew. Chem., Int. Ed. Engl. 38, 2800 (1999).

[23] R. W. Cahn, Nature (London) 410, 643 (2001).

[24] D. Wolf, O. V. Buyevskaya, and M. Baerns, Appl. Catal. A 200, 63 (2000). 